\title{
Study of micro-albuminuria in diabetic nephropathy
}

\author{
Shivakumar ${ }^{1}$, K. Prathibha Bharathi², P.Aruna ${ }^{3}$ J. N. Naidu ${ }^{4}$, M. Prasad ${ }^{5, *}$ \\ ${ }^{1,3}$ Assistant Professor, ${ }^{2}$ Chief Consultant, ${ }^{3}$ Professor \& HOD, ${ }^{4} \mathrm{PhD}$ Scholar, Dept. of Biochemistry, ${ }^{\mathbf{1}}$ Sri Siddartha Medical \\ College \& Hospital, Agalakote, Tumkur, Karnataka, ${ }^{2}$ Apollo \& Hospital, Nellore, Andhra Pradesh, ${ }^{3}$ ACSR Government Medical \\ College and Hospital, Nellore, Andhra Pradesh, ${ }^{4,5}$ Narayana Medical College and Hospital, Nellore, Andhra Pradesh, India
}

Received: $23^{\text {rd }}$ November, 2017

*Corresponding Author:

Email: drmprasad@narayanamedicalcollege.com

Accepted: 02 ${ }^{\text {nd }}$ January, 2018

\begin{abstract}
The prevalence of diabetes mellitus is increasing worldwide. Recent studies showed that India has got large number of diabetic patients. Diabetic nephropathy (DN) develops in $30 \%$ to $40 \%$ of patients with type 1 diabetes mellitus and in $10 \%$ to $20 \%$ of patients with type 2 diabetes mellitus. Diabetic nephropathy is the leading cause of end-stage renal disease (ESRD) worldwide. An early sign of impending nephropathy is microalbuminuria. A total number of 90 samples were analyzed to study the microalbumin levels in 30 diabetic nephropathy patients, 30 diabetic patients without nephropathy and 30 healthy controls. The mean and standard deviation were calculated for all the parameters. The significance between the groups were determined using Student - test for Equality of means. The results show increase in mean concentration of microalbumin in diabetic nephropathy cases when compared to controls and was statistically highly significant $(\mathrm{p}<0.001)$. The results were statistically significant $(\mathrm{p}<$ 0.001) in mean levels of Microalbumin in diabetic nephropathy cases when compared to diabetes mellitus without nephropathy cases.
\end{abstract}

Keywords: Micro albumin, Diabetic nephropathy, proteinuria, End Stage Renal Disease.

\section{Introduction}

Diabetes Mellitus (DM), a life-long progressive disease, is a metabolic disorder of multiple etiology characterized by chronic hyperglycemia with disturbances of blood glucose, fat and protein metabolism resulting from defects in insulin secretion, insulin action, or both. ${ }^{1}$ The chronic hyperglycemia of diabetes is associated with significant long term consecution particularly damage and failure of various organs like kidneys, eyes, nerves, heart and blood vessels. The disease has reached epidemic proportions and has become one of the most challenging health problems of the $21^{\text {st }}$ century. ${ }^{2}$ The prevalence of DM is increasing worldwide with estimated projection of approximately 300 million patients worldwide by year $2025 .^{3}$ The prevalence of DM is rising alarmingly in India too. ${ }^{4}$ According to the most recent estimates published in the Diabetes Atlas. India has the largest number of diabetic patients in the world, estimated to be 40.9 million in the year 2007, 50.8 million for year 2010 and expected to increase to 69.9 million by the year 202.5 The classical definition of diabetic nephropathy is a progressive rise in urine small amount albumin excretion, coupled with increasing blood pressure and pulse pressure, leading to declining GFR and eventually end stage kidney failure. Patients generally have diabetic retinopathy. ${ }^{6}$

The prevalence of type 2 diabetes is about 9-10 times higher than that of type 1 diabetes. Diabetic nephropathy (DN) develops in $30 \%$ to $40 \%$ of patients with type 1 diabetes mellitus and in $10 \%$ to $20 \%$ of patients with type 2 diabetes mellitus. Diabetic nephropathy is related to the leading cause of EndStage Renal Disease (ESRD) worldwide. ${ }^{7}$ An early sign of impending nephropathy is microalbuminuria, which is defined as the urinary excretion of albumin at the rate of $30-299 \mathrm{mg} / 24 \mathrm{hr}$, that cannot be detected with the use of a urine analysis dipstick. The presence of microalbuminuria predicts worsening of renal disease to overt diabetic nephropathy. ${ }^{8}$ Inflammation plays a major role in the pathogenesis of type 2 diabetes mellitus and its complications. ${ }^{9}$

Diabetic Vasculopathy (DV) is a broad subject comprising micro-vascular complications of Diabetes Mellitus such as diabetic neuropathy, diabetic nephropathy (DN), diabetic retinopathy and macrovascular complications of Diabetes Mellitus such as cardio-vascular disease (CVD), cerebro-vascular disease and peripheral vascular disease (PVD). Microvascular and macro-vascular complications are equally important because they are the major cause of mortality and morbidity in patients with DM. The most important cause of mortality in patients with DM is CVD. The micro-vascular and macro-vascular complications do not occur in isolation and often may co-exist. The presence of one may be indicative of the presence of the other and requires further investigation to assess the status of the other systems.

Diabetic nephropathy (DN) is a long-term microvascular complication of diabetes. With increased life expectancy of patients with diabetes, due to improved healthcare, Diabetic nephropathy has became the leading cause of end-stage renal disease (ESRD) worldwide. Diabetic nephropathy in type $2 \mathrm{DM}$ is similar to nephropathy in type $1 \mathrm{DM}$ with similarly 
pathology, response to interventions of glucose control and anti-angiotensin II therapy, and progression to chronic kidney failure. ${ }^{10}$ Five stages of DN have been defined, as the first of which involves the development of glomerular hyper filtration. This is followed by silent stage, incipient nephropathy with microalbuminuria, increased proteinuria and finally ESRD. ${ }^{11}$

Micro-albuminuria is the first detectable clinical sign of an increased risk of DN. ${ }^{12}$ Incipient nephropathy is first manifested by the onset of persistent microalbuminuria. Over a period of time, progressive microalbuminuria may lead to persistent proteinuria, also termed as overt diabetic nephropathy ${ }^{13}$. Microalbuminuria is a marker for diabetic nephropathy and cardiovascular disease in patients with type 1 and type 2 diabetes mellitus. ${ }^{14}$ However, the presence of microalbuminuria in type $2 \mathrm{DM}$ may be more reflective of generalized vascular disease than diabetic glomerulopathy. The urine dipstick is a relatively insensitive marker for proteinuria, not becoming positive until protein excretion exceeds 300 to 500 $\mathrm{mg}$ /day (upper limit of normal equals less than $150 \mathrm{mg}$, with most subjects being under $100 \mathrm{mg}$ ). Using a specific assay for albumin is a more sensitive technique. The normal rate of albumin excretion is less than $20 \mathrm{mg} /$ day $(15 \mathrm{~g} / \mathrm{min})$, persistent albumin excretion between 30 and $300 \mathrm{mg} /$ day (20 to 200 $\mu \mathrm{g} / \mathrm{min}$ ) is called micro-albuminuria. Values above 300 $\mathrm{mg} /$ day $(200 \mu \mathrm{g} / \mathrm{min})$ are considered to represent overt proteinuria. Establishing the diagnosis of microalbuminuria requires the demonstration of a persistent elevation in albumin excretion. Fever, exercise, heart failure, and poor glycemic control are among the factors that can cause transient micro-albuminuria ${ }^{15}$. One problem with measuring the albumin concentration alone or estimating it with a sensitive dipstick is that false negative and false positive results can occur since the albumin concentration (but not the rate of albumin excretion) is also influenced by the urine volume ${ }^{16}$. The effect of volume can be avoided entirely by calculation of the albumin-to-creatinine ratio in an untimed urine specimen. A value above $30 \mathrm{mg} / \mathrm{g}$ (or $0.03 \mathrm{mg} / \mathrm{mg}$ ) suggests that albumin excretion is above $30 \mathrm{mg} /$ day and therefore that micro-albuminuria is probably present. ${ }^{17}$ Both must be measured on at least two of three measurements over a two- to three-month period. Use of the albumin-to-creatinine ratio in an untimed urinary sample is now recommended as the preferred screening strategy for all diabetic patients. ${ }^{18}$ Because of the insidious onset of type $2 \mathrm{DM}$, the true duration of the disease is often not known. It has been reported that duration of about 6 years of diabetes may have existed before diagnosis. ${ }^{19}$ Because of the variable duration of disease at diagnosis, subjects often present with microalbuminuria at that point. Attempts at prevention of nephropathy in type $2 \mathrm{DM}$ have focused on the prevention of micro-albuminuria, the earliest clinical hallmark of nephropathy, or its progression to macroalbuminuria. ${ }^{20}$

\section{Materials and Methods}

The study was conducted over a period of one year. The study includes thirty (30) diagnosed diabetic nephropathy subjects and thirty (30) diagnosed diabetic subjects without nephropathy from medicine, nephrology and endocrinology departments (includes both in-patients and out-patients) of Narayana medical college and Hospital, having diabetic duration of above 10 years and below 10 years respectively. Thirty (30) healthy age, sex matched subjects were selected as control. Institutional ethical committee of Narayana Medical College and Hospital, Nellore Andhra Pradesh have approved the study and informed consent obtained from the patients. The data on family history and personal history of diabetes, smoking habits, alcohol consumption and hypertension and treatment history for diabetes were collected through standard questionnaire. All were given informed consent. Urinary microalbuminuria is studied in diabetic nephropathy cases. Urine micro-albumin by plain bottle blood samples were separated through centrifugation and serum stored at $-20^{0} \mathrm{C}$ to measure the analytics. Fasting urine sample is collected in sterilized container and $\mathrm{pH}$ of urine is adjusted to 7 . Sodium azide preservative 50 $\mu l$ is added to urine sample for storage up to 1 week.

Estimation of Microalbumin by using Immunoturbidometry method ${ }^{21}$ Reagents are used like Diluent $\left(\mathrm{R}_{1}\right)$ : glycine buffer $100 \mathrm{mmol} / \mathrm{lt} . \quad \mathrm{P}^{\mathrm{H}} 10.0$ sodium azide $0.95 \mathrm{~g} / 1$ and Latex $\left(\mathrm{R}_{2}\right)$ is particles coated goat $\mathrm{IgG}$ with anti human albumin. $\mathrm{P}^{\mathrm{H}} 8.2$ sodium azide 0.95g/1 Microalbumin-CAL used a Calibrator concerning human origin micro albumin concentration is stated on the vial label micro albumin control. Sample should be Fresh urine. It is recommended to adjust the $\mathrm{P}^{\mathrm{H}}$ at 7.0 with $\mathrm{NaOH} / \mathrm{HCl}, 1 \mathrm{~mol} / \mathrm{l}$. Stable 7 days at $2-8^{\circ} \mathrm{c}$ when Sodium azide $\mathrm{I} \mathrm{g} / \mathrm{l}$ is added to prevent contamination.

The procedure reporting like first bring the working reagent and the photometer to $37^{\circ} \mathrm{c}$. Assay condition are (Wave length $540 \mathrm{~nm}$, Temperature $37^{\circ} \mathrm{c}$ ). Adjust the instrument to zero with distilled water. (Pipette in to cuvette,Working reagent (ml) 1.0), Calibrator or sample $(\mu 1)$ 7.0. Mix and read the absorbance immediately $\left(\mathrm{A}_{1}\right)$ and after 2 minutes $\left(\mathrm{A}_{2}\right)$ of the sample addition. Reference values was Up to 15 $\mathrm{mg} / \mathrm{lit}$.

Calculation: $\_\left(\mathrm{A}_{2}-\mathrm{A}_{1}\right)$ Samples_X Calibrator concentration $=\mathrm{mg} / \mathrm{l}$ Albumin.

$\left(A_{2}-A_{1}\right)$ Calibrator 


\section{Results}

A total number of 90 samples were analyzed to study the levels of microalbumin levels in 30 diabetic nephropathy patients, 30 diabetic patients without nephropathy and 30 healthy controls. The mean and standard deviation were calculated for all the parameters. The significance between the groups were determined using Student t- test for Equality of means. The p-value $<0.05$ was considered significant.

The mean value and standard deviation of microalbumin levels in controls $(n=30)$ and diabetic nephropathy cases $(\mathrm{n}=30)$ were $6.93 \pm 2.50 \mathrm{mg} / \mathrm{L}$ and $167.73 \pm 77.44 \mathrm{mg} / \mathrm{L}$ respectively. The mean microalbumin levels were statistically highly significant $(p<0.0001)$ among the two groups as shown in Fig. 1

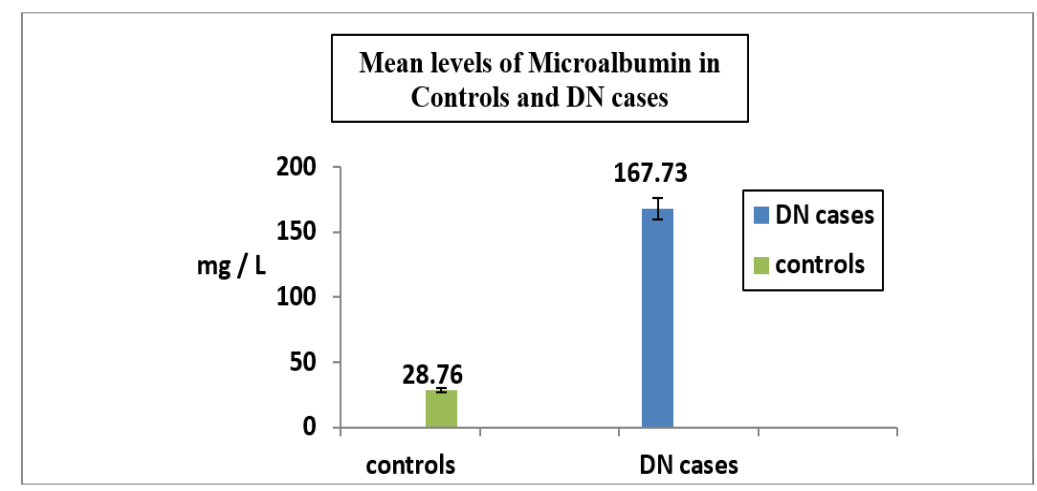

Fig. 1: Mean Microalbumin levels in Controls and DN Cases

The mean value and standard deviation of microalbumin levels in controls and DM without nephropathy cases were $6.93 \pm 2.50 \mathrm{mg} / \mathrm{L}$ and $28.76 \pm 11.57 \mathrm{mg} / \mathrm{L}$ respectively and was statistically highly significant $(\mathrm{p}<0.0001)$ as shown in table (1).

Table 1: Mean Microalbumin levels in Controls and DM without nephropathy cases

\begin{tabular}{|l|c|c|c|c|}
\hline \multirow{2}{*}{ Parameter } & \multicolumn{2}{|c|}{ Groups } & \\
\cline { 2 - 4 } & $\begin{array}{c}\text { Controls(n=30) } \\
\text { Mean } \pm \text { SD }\end{array}$ & $\begin{array}{c}\text { DM without } \\
\text { nephropathy } \\
\text { Cases(n=30) } \\
\text { Mean } \pm \text { SD }\end{array}$ & t value & p value \\
\hline $\begin{array}{l}\text { Microalbumin } \\
\text { mg/L }\end{array}$ & $6.93 \pm 2.50$ & $28.76 \pm 11.57$ & 10.1012 & 0.0001 \\
\hline
\end{tabular}

The mean value and standard deviation of microalbumin levels in DM without nephropathy cases and diabetic nephropathy cases were $28.76 \pm 11.57 \mathrm{mg} / \mathrm{L}$ and $167.73 \pm 77.44 \mathrm{mg} / \mathrm{L}$ respectively and was statistically highly significant $(p<0.0001)$ as shown in table (2).

Table 2: Mean Microalbumin levels in DM without nephropathy and DN cases

\begin{tabular}{|c|c|c|c|c|}
\hline \multirow[b]{2}{*}{ Parameter } & \multicolumn{2}{|c|}{ Groups } & \multirow[b]{2}{*}{ t value } & \multirow[b]{2}{*}{$p$ value } \\
\hline & $\begin{array}{c}\text { DM without } \\
\text { nephropathy } \\
\text { cases }(n=30) \\
\text { Mean } \pm \text { SD }\end{array}$ & $\begin{array}{c}\text { DN } \\
\text { Cases(n=30) } \\
\text { Mean } \pm \text { SD }\end{array}$ & & \\
\hline $\begin{array}{l}\text { Microalbumin } \\
\mathrm{mg} / \mathrm{L}\end{array}$ & $28.76 \pm 11.57$ & $167.73 \pm 77.44$ & 9.7213 & 0.0001 \\
\hline
\end{tabular}

\section{Discussion}

Diabetic nephropathy is a chronic complication of DM with a growing incidence in the subjects. The especially in relation to prevention and aggressive management to avoid progression to End Stage Renal Disease. Besides, its direct association with cardiovascular symptoms makes it imperative to perform intensive, early identify the risk factors. The present study was done at Narayana Medical College and Hospital, Nellore, to study the microalbuminuria in diabetic nephropathy patients. A total number of 90 subjects were studied which included 30 normal healthy subjects, $30 \mathrm{DM}$ without nephropathy cases and 30 diabetic nephropathy cases. In the 90 subjects microalbumin levels were estimated and analyzed. The 
results showed increased mean concentration of microalbumin in diabetic nephropathy cases when compared to controls and was statistically highly significant $(p<0.001)$. The results were statistically significant $(\mathrm{p}<0.001)$ in mean levels of Microalbumin in diabetic nephropathy cases when compared to DM without nephropathy cases. Marre $\mathrm{M}$ et al., ${ }^{22}$ study discussed about Inhibition of angiotensin converting enzyme prevents development of nephropathy in normotensive diabetics with persistent microalbuminuria. This may be due to reduction in intraglomerular pressure and to prevention of increased systemic blood pressure. Future studies should compare long term effects of inhibitors of converting enzyme with other antihypertensive drugs. Wu AY et al, ${ }^{23}$ The high prevalence $(58.6 \%)$ of micro or macroalbuminuria observed in these patients is alarming and indicates an impending pandemic of diabetic cardiovascular and renal diseases in Asia with its potential economic consequences.

\section{Conclusions}

Our study concludes, estimation of microalbuminuria levels in Diabetes Mellitus patients with and without Nephropathy is helpful in assessing the diabetic process and identifying the risk category for complications which are the main causes for mortality and morbidity among diabetes mellitus patients. Such investigations can not only improve the quality of life but also reduce mortality in diabetic patients.

Funding: No funding sources

Conflict of interest: None declared

Ethical approval: The study was approved by the Institutional Ethics Committee

\section{Acknowledgement}

Cooperation with Dept of Biochemistry, Narayana Medical college and Hospital, Chinthareddy palem, Nellore, 524003, Andhra Pradesh, India.

\section{References}

1. Alberti KG, Zimmet PZ. Definition, diagnosis and classification of diabetes mellitus and its complications. Part 1: diagnosis and classification of diabetes mellitus provisional report of a WHO consultation. Diabet Med 1998;15(7):539-53.

2. B Shivanand Nayak et al. correlation of microalbumin and anthropometric variables in type 2 diabetic patients with and without nephropathy. vascular health and risk management 2008;4(1)243-7.

3. King H, Aubert RE, Herman WH. Global burden of diabetes, 1995-2025: prevalence, numerical estimates, and projections. Diabetes Care 1998;21(9):1414-31.

4. Ramachandran A. Epidemiology of diabetes in Indiathree decades of research. J Assoc Physicians India. 2005;53:34-8.
5. S Venugopal, U M Iyer.Risk factor analysis and prevalence of microalbuminuria among type 2 diabetes mellitus subjects: the need for screening and monitoring microalbumin. Asian J. Exp. Biol. Sci. Vol 1 (3) 2010;652-9.

6. Enyioma N Obineche and Abdu Adem. Update in Diabetic Nephropathy. Int J Diabetes and Metabolism 2005;13:1-9.

7. Benjamin A,Margret T,Micheal Adjei.prevalence and predictors of microalbuminuria in patients with diabetes mellitus: A cross-sectional observational study in Kumasi,Ghana.Ethinicity and Disease, Vol 17, Autumn 2007.

8. Krolewski AS, Laffel LM, Krolewski M, Quinn M, Warram JH. Glycosylated hemoglobin and the risk of microalbuminuria in patients with insulin-dependent diabetes mellitus. N Engl J Med 1995;332:1251-5.

9. Schauer R. Sialic acids. Trends Biochem 1985;7:357-60.

10. American Diabetes Association: Nephropathy in diabetes (Position Statement). Diabetes Care 2004;27(1):S79-S83.

11. Mogensen CE, Christensen CK, Vittinghus E. The stages in diabetic renal disease. With emphasis on the stage of incipient diabetic nephropathy. Diabetes 1983;32(2):6478.

12. Keane WF, Brenner BM, de ZD, Grunfeld JP, McGill J, Mitch WE, Ribeiro AB, Shahinfar S, Simpson RL, Snapinn SM, Toto R. The risk of developing end-stage renal disease in patients with type 2 diabetes and nephropathy: the RENAAL study. Kidney Int 2003;63(4):1499-507.

13. Phillips AO, Steadman R. Diabetic nephropathy: The central role of rena proximal tubular cells in tubulointerstitial injury. Histology and Histopathology 2002;17(1):247-52.

14. American Diabetes Association: Nephropathy in diabetes (Position Statement). Diabetes Care 2004;27(1):S79-S83.

15. Gross JL, de Azevedo MJ, Silveiro SP, et al. Diabetic nephropathy: diagnosis, prevention, and treatment. Diabetes Care 2005;28:164.

16. Schwab SJ, Dunn FL, Feinglos MN. Screening for microalbuminuria. A comparison of single sample methods of collection and techniques of albumin analysis. Diabetes Care 1992;15:1581.

17. Nakamura Y, Myers BD. Charge selectivity of proteinuria in diabetic glomerulopathy. Diabetes 1988;37:1202.

18. K/DOQI Clinical Practice Guidelines and Clinical Practice recommendations for diabetes and chronic kidney disease. Am J Kidney Dis 2007;49(2):S17.

19. Harris M, Klein R, Welborn T, and Knuiman M. Onset of NIDDM occurs at least 4-7 years before clinical diagnosis. Diabetes Care 1992;15:815-9.

20. Palmer JP. Insulin autoantibodies: their role in the pathogenesis of IDDM. Diabetes Metab Rev 1987;3(4):1005-15.

21. Bernard a, lauwerys $r$. Latex immunoassay of urinary albumin. J clin chem. Clin biochem 1983; 21(1):25-0.

22. Marre M, Chatellier G, Leblanc H, Guyene TT, Menard J, Passa P. Prevention of diabetic nephropathy with enalapril in normotensive diabetics with microalbuminuria. Bmj. 1988 Oct 29;297(6656):1092-5.

23. Wu AY, Kong NC, De Leon FA, Pan CY, Tai TY, Yeung VT, Yoo SJ, Rouillon A, Weir MR, MAPS Investigators. An alarmingly high prevalence of diabetic nephropathy in Asian type 2 diabetic patients: the MicroAlbuminuria Prevalence (MAP) Study. Diabetologia. 2005 Jan 1;48(1):17-26. 